\title{
Partial transport in a natural gravel bed channel
}

\author{
Judith K. Haschenburger \\ School of Geography and Environmental Science, University of Auckland, Auckland, New Zealand
}

Peter R. Wilcock

Department of Geography and Environmental Engineering, Johns Hopkins University, Baltimore, Maryland, USA

Received 19 June 2002; revised 3 November 2002; accepted 8 November 2002; published 28 January 2003.

[1] Partial transport is documented in the gravel bed channel of Carnation Creek using magnetically tagged stones. For four flood peaks the active proportion of surface grains was used to map streambed areas into distinct units of three different levels of grain entrainment. In partially mobile regions of the bed, the active proportion of surface grains declines with grain size. As flow increases, areas of partial transport grow at the expense of inactive areas and fully active areas replace areas with partial mobility. Approximately $25-50 \%$ of the bed remained in a state of partial mobility during a flood with a 2-year return period, indicating that inactive regions of the bed surface typically persist from year to year. During a flood with a 7-year return period, surface grain entrainment was nearly complete, indicating that full mobilization of surface grains is not a frequent

event. INDEX TERMS: 1815 Hydrology: Erosion and sedimentation; 1821 Hydrology: Floods; 1824

Hydrology: Geomorphology (1625); KEYWORDS: partial transport, surface grain entrainment, tracers,

sediment exchange

Citation: Haschenburger, J. K., and P. R. Wilcock, Partial transport in a natural gravel bed channel, Water Resour. Res., 39(1), 1020, doi:10.1029/2002WR001532, 2003.

\section{Introduction}

[2] At base flow in gravel bed rivers, little, if any, sediment transport occurs, with the possible exception of sand overpassing with little exchange with the bed. As flow increases, both the number and size of grains entrained from the bed surface increase until a flow is reached that entrains all grains on the bed surface. Identification of the variation of grain entrainment with flow has important implications for the rates and frequency of sediment sorting and streambed armoring, for flushing of fine sediments from the bed subsurface, and for defining benthic disturbance in gravel bed rivers.

[3] The condition in which some surface grains remain immobile over the duration of a transport event has been defined as partial transport [Wilcock and McArdell, 1993, 1997]. Grains that are never entrained over a transport event are termed "inactive" to distinguish them from the remainder of the surface grains that are occasionally entrained and therefore "active," because even active grains typically spend most of the time immobile. Partial transport may be defined relative to the bed as a whole, indicating the active portion of all grains on the bed surface, or relative to individual size fractions, indicating the active proportion of surface grains of a given size. Grains in smaller size fractions may be active during a flow event that entrains none or only a portion of the grains in larger size fractions, such that the finer fractions may be described as being fully mobilized while the coarser fractions are inactive or in a state of partial transport. In laboratory observations with a

Copyright 2003 by the American Geophysical Union. 0043-1397/03/2002WR001532\$09.00 sand/gravel mixture, Wilcock and McArdell [1997] found that the range in flow over which all grains in a size fraction became active was approximately a factor of 2 in shear stress and the range of sizes in a state of partial transport at a given flow was approximately a factor of 2 .

[4] Observations of partial transport remain largely those at the detailed scale of the laboratory flume [Wilcock and McArdell, 1993, 1997], where the active proportion of surface grains was determined from photographic analysis of color-coded sediment over a range of bed shear stresses. Observation of partial transport in the field is more difficult due to limited access and to the much greater spatial variability in bed topography and composition. Available observations are from studies using tracer stones [Stelczer, 1981; Andrews and Erman, 1986; Carling, 1987; Ashworth and Ferguson, 1989; Ferguson and Wathen, 1998; Church and Hassan, 2002] and ad hoc observations of natural surface staining [Wilcock et al., 1996]. A related study used measured bed-material size and channel topography and a computed three-dimensional flow field in six gravel bed rivers located in northwestern California and western Colorado to determine the distribution of dimensionless shear stress $\left(\tau^{*}\right)$ and regions of surface grain activity defined as stable $\left(\tau^{*}<0.03\right)$, partially mobile $\left(0.03<\tau^{*}<0.06\right)$, and fully mobile $\left(\tau^{*}>0.06\right)$ [Lisle et al., 2000].

[5] Under partial transport conditions, both lab and field studies suggest that the active proportion of surface grains declines with grain size [Andrews and Erman, 1986; Ashworth and Ferguson, 1989; Wilcock and McArdell, 1993, 1997; Church and Hassan, 2002]. These studies do not provide much indication of how the spatial extent of partial transport varies with discharge, although other measurements of streambed activity demonstrate that the area of 
active transport increases with flow [Jackson and Beschta, 1982; Haschenburger and Church, 1998]. Together, these observations suggest that an increase in discharge will shift partial transport from finer to coarser sizes and cause partial transport to migrate from regions of relatively large stress to regions of relatively smaller stress.

[6] There is a clear connection between partial transport and sediment transport rate. Only active grains contribute to the transport, and an increase in flow will increase both the proportion of entrained surface grains and the transport rate. Nonetheless, important distinctions between the two must be understood in order to avoid misinterpretations. Transport rates depend not only on the population of grains participating in the transport, but also on the entrainment frequency and the distance traveled by active grains. Substantial transport rates of all grain sizes found on the bed surface can be produced under conditions for which the bed is only partially mobile [Wilcock and McArdell, 1997]. The observation that all sizes are found in transport cannot be used to conclude that the bed has been entirely entrained.

[7] Partial transport is an explicitly local description, describing the activity of a particular location on the bed, whereas the provenance of sediment transported past a bed location is generally not known. Observations of local transport do not necessarily indicate local entrainment [Lisle et al., 2000; Church and Hassan, 2002]. Source areas for transported sediment may extend over a significant length of the channel [Hassan et al., 1991], well beyond the reach immediately upstream of the transport sampling area [Andrews, 1983; Carling, 1989].

[8] An improved description of partial transport under field conditions is needed to understand physical and biological processes that depend on the degree of grain entrainment. Streambed armoring depends directly on the proportion of the bed surface that is mobilized and actively participating in the vertical sorting process. Similarly, the degree of partial transport controls the amount of time required for the streambed to adjust to changes in water or sediment supply. For example, a streambed in a state of partial transport during a 2-year or 5-year flood will adjust to changing water or sediment supply more slowly than one that is fully mobile during an annual flood. Flushing of fines from the bed subsurface also depends directly on the entrained proportion of coarse grains on the bed surface. Where flushing flows are an option, specification of an effective discharge should be based on the proportion of the bed entrained, rather than on the transport rate [Wilcock, 1998]. If complete surface entrainment is a rare event, prevention of fines infiltration takes on increased importance in developing streambed restoration plans (e.g., in support of salmonid restoration). The frequency and extent of partial transport also play a direct role in defining the disturbance regime for benthic organisms. For example, if a state of partial transport persists from year to year, a portion of the benthic population is likely to survive flood conditions in place and mobile organisms are more likely to successfully find local refugia [Kenworthy and Wilcock, 2001].

[9] Many gravel bed rivers in nonarid environments have relatively modest transport rates, even in floods with a return period of multiple years, suggesting that partial transport is a common condition and may persist from year to year. Even if all sizes are found in the transport during floods, the possibility remains that only a portion of the bed surface was actually mobilized. The extent to which partial transport occurs in field is not well understood. In the available studies, small numbers of tagged stones or limited flow conditions and transport rates restrict the ability to develop a quantitative summary of partial transport and its variation with flow.

[10] The objective of this paper is to take advantage of an unusually extensive tracer gravel experiment [Haschenburger, 1996] to document partial transport conditions in the field. We examine the spatial extent of partial transport and explore how it varies with discharge. To the degree possible, we relate the extent of partial transport to the frequency of the observed flows in order to evaluate the bed disturbance regime. We also examine how partial transport varies with grain size as part of a description of active and inactive areas of the bed.

\section{Study Area}

[11] Observations are drawn from Carnation Creek, a gravel bed stream that drains an area of about $11 \mathrm{~km}^{2}$ on the west coast of Vancouver Island, Canada. Between 1975 and 1981, experimentally prescribed logging [Dryburgh, 1982; Scrivener, 1987] removed $41 \%$ of the overmature forest dominated by western hemlock (Tsuga heterophylla), amabilis fir (Abies amabilis), and western red cedar (Thuja plicata) [Oswald, 1982] in the lower basin. Most clear-cut areas were subsequently planted with tree seedlings. An additional $20 \%$ of the forest was logged in the upper portion of the basin between 1987 and 1993 [Lewis, 1998].

[12] Frequent cyclonic storms deliver about $3200 \mathrm{~mm}$ of precipitation annually to the basin primarily between October and March. Rapid hydrologic response to storm events produces flood hydrographs with short times to peak. Two Water Survey of Canada gauges, one located near the basin outlet (08HB048) and the other on a tributary (08HB069) that enters the study reach, provide continuous streamflow records for discharge estimation in the study reach. For the channel upstream of the gauged tributary, the 2-year flood peaks at $30 \mathrm{~m}^{3} \mathrm{~s}^{-1}$. Bank-full discharge was estimated as approximately $35 \mathrm{~m}^{3} \mathrm{~s}^{-1}$ by reconstructing flow depths [Haschenburger, 1999], but no field observation is available to strictly verify this value.

[13] Channel planform consists of relatively straight reaches punctuated by sharp bends, which are, at places, forced by resistant bank material or bedrock outcrops. In the 900m-long study reach, located about $2 \mathrm{~km}$ from the basin outlet, the channel exhibits bar-riffle-pool morphology over a mean streambed gradient of 0.009 . Avalanche faces on some of the gravel bars indicate their downstream mobility. Bank-full width and depth average 15 and $1 \mathrm{~m}$, respectively. Diameters of the 50th $\left(D_{50}\right)$ and 90th $\left(D_{90}\right)$ percentiles of surface sediment are 47 and $120 \mathrm{~mm}$, respectively, while those for subsurface sediment are 29 and $112 \mathrm{~mm}$, respectively. Sand-sized grains make up $<10 \%$ of subsurface sediment, on average, and are not commonly found in large quantities on the bed surface. The content of both clay and silt in the subsurface does not exceed $1 \%$. In general, mass wasting (bank collapse, debris flows, landslides) appears to supply the major inputs of fine sediment to the channel, but the failure of logjams occasionally releases large quantities 
of previously trapped sediment, some of which can travel in suspension [Church, 1998].

[14] Reach-based transport rates for bed material averaged 0.022 and $0.12 \mathrm{~kg} \mathrm{~m}^{-1} \mathrm{~s}^{-1}$ for flood events that peaked at 17.7 and $36.3 \mathrm{~m}^{3} \mathrm{~s}^{-1}$, respectively, as estimated using tracer gravels and scour indicators in a virtual grain velocity approach (see Haschenburger and Church [1998] for details). Several accumulations of large woody debris exist in the study reach. Magnetically tagged gravels document that these jams are permeable to the gravel sizes present in the channel.

\section{Field Methods}

[15] To record surface grain entrainment, magnetically tagged stones were deployed from two locations (Figure 1) in the study reach. These locations are representative of the relatively straight segments of the study reach in terms of channel characteristics and stability. Surface grain sizes in the seeded reaches tend to be coarser than the reach average (upper area: $D_{50}=55 \mathrm{~mm}, D_{90}=106 \mathrm{~mm}$; lower area: $D_{50}=$ $67 \mathrm{~mm}, D_{90}=140 \mathrm{~mm}$ ).

[16] Tracers were deployed in five groups on three occasions between August 1991 and August 1992 (Table 1). Four of the five tracer groups (A, B, D, E) consisted of approximately 500 stones each, placed in four lines spaced $0.8 \mathrm{~m}$ apart (about 3 times the largest tracer size). All tracers were released on the streambed surface, with half of the tracers added among existing surface grains and the other half substituted for naturally positioned stones of similar size. All tracers in group A replaced existing stones, and all tracers in group B were added to the surface. Groups D and E consisted of two lines each of added and substituted tracers. Tracers were evenly distributed along deployment lines that extended across the streambed, although replaced tracers exhibited less uniform spacing and spatial distribution of sizes because of the need to find similar sized stones. Crosssectional tracer density averaged about 12 stones $\mathrm{m}^{-1}$. Groups A, B, D, and E each covered a streambed area of about $20 \mathrm{~m}^{2}$. Group $\mathrm{C}$ was a smaller supplemental deployment of 158 tracers that covered about $4 \mathrm{~m}^{2}$ of the streambed located within the $1.5-\mathrm{m}$ streamwise distance separating groups $\mathrm{A}$ and $\mathrm{B}$.

[17] Tracers ranged in size from 16 to $180 \mathrm{~mm}$. The tracer size distribution matched that of the subsurface size distribution, except in the 16- and 22-mm size classes, which were augmented to improve the likelihood of recovery. The supplemental group $\mathrm{C}$ tracers comprised grains $<128 \mathrm{~mm}$ except for ten $180-\mathrm{mm}$ clasts. The 32 - to $180-\mathrm{mm}$ tracers consisted of natural stones implanted with ceramic magnets and identification labels. Because of the difficulty of drilling into small stones, the two smallest fractions were fabricated with epoxy embedded with magnets and lead shot, the latter needed to achieve a typical density of natural rock. Grain shape was within the range found in natural stones, but ratios of intermediate to short axes were smaller than average.

[18] Tracers were recovered by searching the streambed with a magnet detector. Streamwise coordinates determined from a measuring tape positioned down the center of the channel were paired with crosswise coordinates measured laterally from the center tape. Bench marks registered the center tape position between recoveries. All tracers were replaced in their found positions for subsequent tracing.
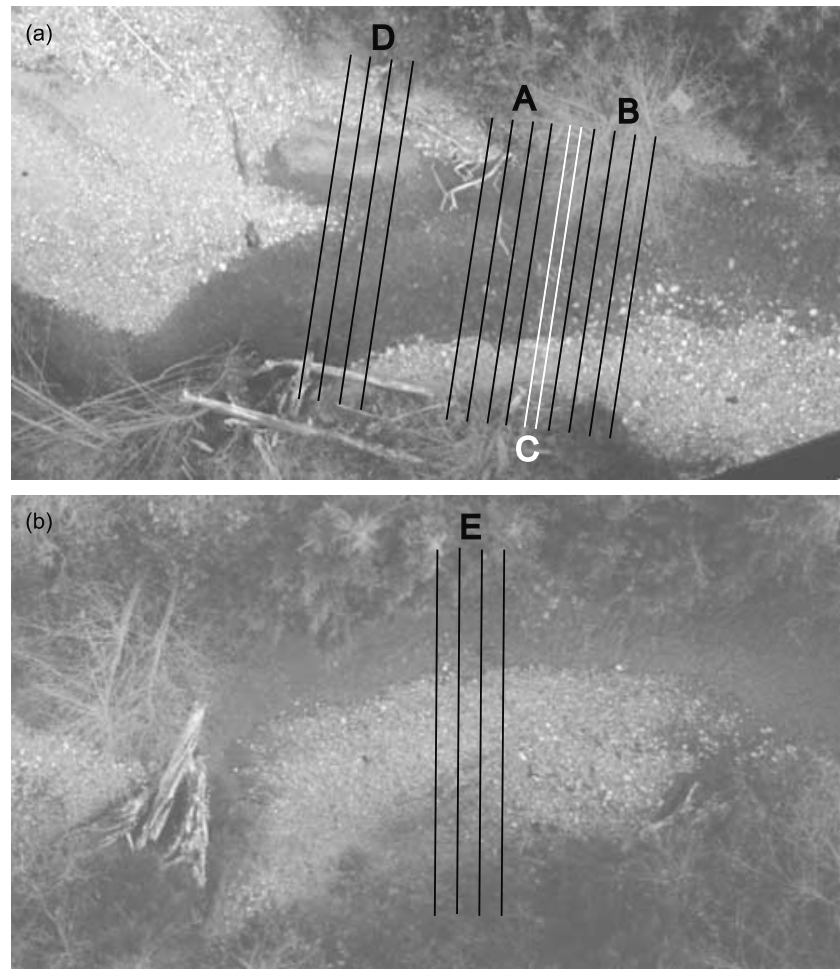

Figure 1. Tracer deployment areas: (a) upper and (b) lower. The upper area consists of monitored bed areas A-D and is located $410 \mathrm{~m}$ upstream of the gauged tributary that enters the study reach. The lower area consists of monitored bed area E, which is located $130 \mathrm{~m}$ upstream of the gauged tributary and about $20 \mathrm{~m}$ downstream of a logjam that is permeable to sediment. Flow is from left to right.

[19] Observation of partial transport does not require relocation of grains, only verification of movement. Individual partial transport observations consisted of documenting the position of surface tracers at a particular time, followed by a resurvey locating inactive grains after a high flow had occurred. Inactive grains were defined as those that moved less than $1 \mathrm{~m}$. With naturally worked sediment, grain entrainment would be underestimated using this criterion, but with tracers, it provides some compensation for the increased propensity for entrainment with the first flood after deployment and acknowledges the measurement resolution of tracer coordinates. Most grains classified as immobile did not move at all within the resolution (approximately $30 \mathrm{~cm}$ ) of relocation. Tracers not found during recoveries were assumed to be entrained, given the low probability of deep in situ burial in the deployment areas. Upon initial deployment of tracer grains, a partial transport observation consists entirely of artificially placed grains; subsequent observations are based on a mixed population of grains still in their initial position and grains previously moved and relocated. Size distributions of in situ tracers coarsened over time. However, partial transport observations were developed only for floods of increasing magnitude and therefore more extensive entrainment, so the classification of bed areas into different entrainment levels was probably not affected by the increasing mean size of tracers.

[20] Repeat surveys at benchmarked cross sections recorded adjustments in bed elevation after individual 
Table 1. Tracer Deployment and Recovery

\begin{tabular}{|c|c|c|c|c|c|c|c|}
\hline \multirow[b]{3}{*}{ Date } & \multirow{3}{*}{$\begin{array}{l}\text { Tracer } \\
\text { Activity }\end{array}$} & \multirow{3}{*}{$\begin{array}{l}\text { Peak Discharge, } \\
\mathrm{m}^{3} \mathrm{~s}^{-1}\end{array}$} & \multicolumn{5}{|c|}{ Number of Tracers } \\
\hline & & & \multicolumn{4}{|c|}{ Upper Area } & \multirow{2}{*}{$\begin{array}{l}\text { Lower } \\
\text { Area, E }\end{array}$} \\
\hline & & & A & B & $\mathrm{C}$ & $\mathrm{D}$ & \\
\hline 23 Aug. 1991 & deployment & & 498 & 489 & & & \\
\hline 29 Aug. 1991 & & 24.5 & & & & & \\
\hline 19 Sept. $1991^{\mathrm{a}}$ & recovery $^{\mathrm{b}}$ & & 47 & 75 & & & \\
\hline 19 Oct. 1991 & deployment & & & & 158 & & \\
\hline 19 Nov. 1991 & & 30.4 & & & & & \\
\hline 23 Jan. 1992 & & 21.9 & & & & & \\
\hline 29 Jan. 1992 & & 22.6 & & & & & \\
\hline 30 June $1992^{a}$ & recovery ${ }^{\mathrm{b}}$ & & 29 & 61 & 8 & & \\
\hline 30 Aug. 1992 & deployment & & & & & 495 & 495 \\
\hline 20 Oct. 1992 & & 17.7 & & & & & \\
\hline 11 Dec. $1992^{a}$ & recovery ${ }^{\mathrm{b}}$ & & 47 & 64 & 9 & 119 & 143 \\
\hline 24 Jan. 1993 & & 36.3 & & & & & \\
\hline 4 March 1993 & & 17.9 & & & & & \\
\hline 22 March 1993 & & 13.6 & & & & & \\
\hline 20 July $1993^{a}$ & recovery ${ }^{\mathrm{b}}$ & & 2 & 7 & 1 & 1 & 1 \\
\hline
\end{tabular}

${ }^{a}$ Recovery required $1-3$ days. Date shown is last day of recovery.

${ }^{b}$ Number of surface tracers in monitored bed areas for each recovery. These form starting number for subsequent observation period. Tracer counts include surface tracers remaining within deployment areas, movement of tracers into monitored streambed areas from upstream locations, and in some cases, exposure of previously buried tracers through local net scour.

floods. Streambed topography was characterized by mapping the study reach during summer base flow conditions.

\section{Mapping Surface Grain Activity}

[21] Partial transport was documented over four time periods, each with a different peak discharge (Table 1). Tracer groups A and B record entrainment from four floods, three of which occur in increasing order of peak discharge and provide useful partial transport information. The smallest of the four floods $\left(17.7 \mathrm{~m}^{3} \mathrm{~s}^{-1}\right)$ is third in order and provides negligible information on partial transport because a large but unknown proportion of marked grains that might have remained inactive if this flood peak had occurred first in the sequence had already been removed from the site by the preceding larger floods. Tracer groups D and E record entrainment from two floods (Table 1). Tracer group C served only as a supply of marked grains to the deployment area containing group B. In some cases, other smaller floods occurred during an observation period (Table 1). We assumed that entrainment produced by these smaller floods was small compared with that produced by the largest peak flood in a given period, which is supported by the relatively large difference in the peak discharges within a given period.

[22] On the basis of deployment and recovery information, planimetric maps showing tracer mobility (e.g., Figure 2a) were constructed for each recovery at all streambed areas. Tracer activity was described by calculating the active proportion of surface grains $(Y)$ within 1-m increments along deployment lines. Given the decline in tracer numbers in the deployment areas over time, and hence the mapping resolution feasible, a $1-\mathrm{m}$ increment provided the most consistent delineation of regions of bed mobility between activity maps. In the streamwise direction, tracer lines served as end boundaries for the intervening area of the streambed. The active proportion for the intervening sub- areas was determined by averaging local $Y$ between adjacent deployment lines.

[23] Three levels of surface grain activity, immobile $(Y<$ $0.1)$, partially mobile $(0.1 \leq Y \leq 0.9)$, and fully mobile $(Y>$ $0.9)$, were used to partition the streambed area. Interpolated boundaries between calculated subarea activity levels were made linear for simplicity and consistency between maps.

[24] Because fewer surface tracers were available for mapping recoveries 2 and 4 (Table 1), partition of the streambed area also relied on the assumption that activity levels in a given bed area were at least equal to that of a preceding smaller flood, unless tracer evidence suggested otherwise. Given the relative bed stability of the deployment areas, it seems reasonable that a comparable level of activity would be reached and more likely exceeded in response to increased flood magnitude. In some cases, observed mobility of buried tracers could be used to verify this mapping strategy. Because these later maps rely, in part, on reworked tracers, there may be some shift in entrainment threshold stresses relative to maps based on the first recovery after tracer deployment.

[25] The sensitivity of mapping results was evaluated relative to the choice of $Y$ class limits $(0.1$ and 0.9 versus 0.2 and 0.8$)$, crosswise width increment $(0.25,0.5$, and $1 \mathrm{~m})$, and the streamwise boundary used to map activity between deployment lines (along tracer lines versus midway between lines). Although these choices changed some details, the overall trends described were not affected significantly. In
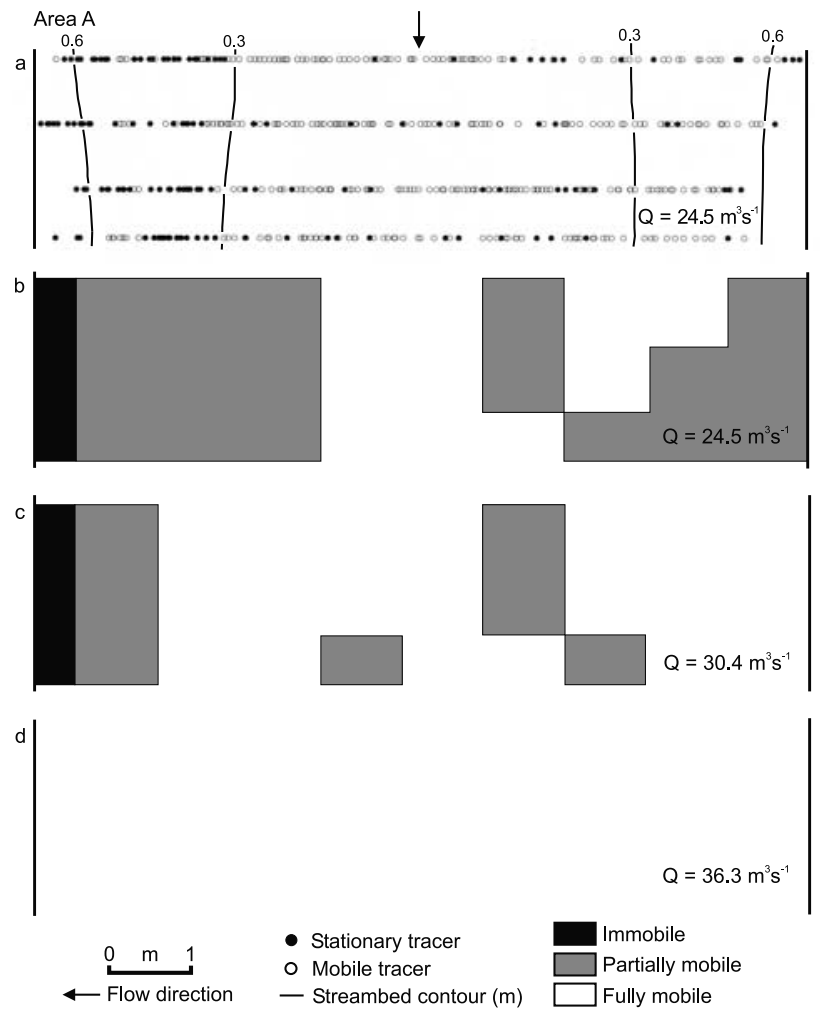

Figure 2. Maps for bed area A in upper deployment area. (a) Map indicating mobility of individual tracers for the 24.5 $\mathrm{m}^{3} \mathrm{~s}^{-1}$ peak and activity maps for (b) $24.5 \mathrm{~m}^{3} \mathrm{~s}^{-1}$ peak, (c) $30.4 \mathrm{~m}^{3} \mathrm{~s}^{-1}$ peak, and (d) $36.3 \mathrm{~m}^{3} \mathrm{~s}^{-1}$ peak. 
Table 2. Areas of Activity Levels

\begin{tabular}{|c|c|c|c|c|c|c|c|c|}
\hline \multirow[b]{2}{*}{ Deployment Area } & \multirow[b]{2}{*}{ Bed Area } & \multirow[b]{2}{*}{ Flood Peak, $\mathrm{m}^{3} \mathrm{~s}^{-1}$} & \multicolumn{2}{|c|}{ Immobile } & \multicolumn{2}{|c|}{ Partially Mobile } & \multicolumn{2}{|c|}{ Fully Mobile } \\
\hline & & & Area, $\mathrm{m}^{2}$ & Proportion & Area, $\mathrm{m}^{2}$ & Proportion & Area, $\mathrm{m}^{2}$ & Proportion \\
\hline \multirow[t]{8}{*}{ Upper } & A & 24.5 & 1.1 & 0.053 & 12.4 & 0.59 & 7.4 & 0.35 \\
\hline & & 30.4 & 1.1 & 0.053 & 5.0 & 0.24 & 14.8 & 0.71 \\
\hline & & 36.3 & 0 & 0 & 0 & 0 & 20.9 & 1.0 \\
\hline & $\mathrm{B}$ & 24.5 & 0 & 0 & 13.2 & 0.58 & 9.6 & 0.42 \\
\hline & & 30.4 & 0 & 0 & 11.2 & 0.49 & 11.6 & 0.51 \\
\hline & & 36.3 & 0 & 0 & 2.4 & 0.10 & 20.4 & 0.90 \\
\hline & $\mathrm{D}$ & 17.7 & 0.4 & 0.018 & 13.6 & 0.60 & 8.8 & 0.38 \\
\hline & & 36.3 & 0 & 0 & 0 & 0 & 22.8 & 1.0 \\
\hline \multirow[t]{2}{*}{ Lower } & $\mathrm{E}$ & 17.7 & 1.6 & 0.072 & 12.8 & 0.58 & 7.8 & 0.35 \\
\hline & & 36.3 & 0 & 0 & 2.4 & 0.11 & 19.8 & 0.89 \\
\hline
\end{tabular}

general, we opted for measures that tended to provide greater spatial averaging rather than greater spatial detail.

[26] To evaluate the relation between fractional active proportion $\left(Y_{i}\right)$ and grain size $\left(D_{i}\right)$ for a given map, $Y_{i}$ was calculated after pooling tracer data from all locations with a given activity level. Only first floods after major tracer deployments (groups A and B, recovery 1 and groups D and E, recovery 3) were considered because they provided sufficient sample sizes to calculate grain size-specific trends. Although these floods may return biased results due to artificial placement of tracers, the differential response between grain sizes should be consistent.

\section{Results}

[27] In deployment area A, the first flood peak of $24.5 \mathrm{~m}^{3}$ $\mathrm{s}^{-1}$ produced partial mobility over $59 \%$ of the bed and full mobility over $35 \%$ of the bed (Figure $2 b$; Table 2 ). The zone of partial mobility consisted of the multiple, individual units that exhibited the largest area per unit of the three activity levels. Full mobility units adjoined partially mobile areas, and the largest unit encompassed the thalweg. Grain immobility was confined to a narrow region along the right bank where the bed elevation is about $0.8 \mathrm{~m}$ above the thalweg. The narrow immobile region persisted through the $30.4 \mathrm{~m}^{3}$ $\mathrm{s}^{-1}$ flood, whereas the fully mobile area increased to $71 \%$ of the bed area at the expense of the partially mobile area (Figure 2c). The increased number of smaller individual units of partial mobility documents a decrease in spatial continuity for this activity level. At the largest peak of 36.3 $\mathrm{m}^{3} \mathrm{~s}^{-1}$, the entire bed was fully mobile (Figure 2d), indicating complete surface grain entrainment at a flow close to bank-full discharge.

[28] At area $\mathrm{B}$, the $24.5 \mathrm{~m}^{3} \mathrm{~s}^{-1}$ flood produced full mobility over $42 \%$ of the bed, including the thalweg (Figure $3 b)$. The remainder of the bed was partially mobile and consisted of two separate units positioned away from the thalweg on each side of the bed area that reached full mobility (Figure 3b; Table 2). All individual units extended over the full streamwise distance and comprised relatively large areas. At $30.4 \mathrm{~m}^{3} \mathrm{~s}^{-1}$, the fully mobile area expanded to $51 \%$, while the partially mobile area declined to $49 \%$. With this larger discharge the overall spatial continuity of partially mobile areas decreased, as indicated by the increase to three individual units of this activity level (Figure 3c). Some regions classified as fully mobile after the $24.5 \mathrm{~m}^{3} \mathrm{~s}^{-1}$ flow were mapped as partially mobile following the $30.4 \mathrm{~m}^{3} \mathrm{~s}^{-1}$ flow (Figures $3 \mathrm{~b}$ and $3 \mathrm{c}$ ), because a number of large tracers $(>90 \mathrm{~mm})$ transported into these areas by the first flood did not move during the second. At $36.3 \mathrm{~m}^{3} \mathrm{~s}^{-1}, 90 \%$ of the bed was fully mobile, with a small region of partial mobility near the right bank. Although the two nearest surveyed cross sections indicate some bed degradation at the highest flow, only a minor adjustment occurred in thalweg position.

[29] At area D the $17.7 \mathrm{~m}^{3} \mathrm{~s}^{-1}$ flood produced partial mobility over $60 \%$ of the bed and full mobility over the remainder, except for a small immobile region near the left bank (Figure 4b; Table 2). Full mobility was mapped for the
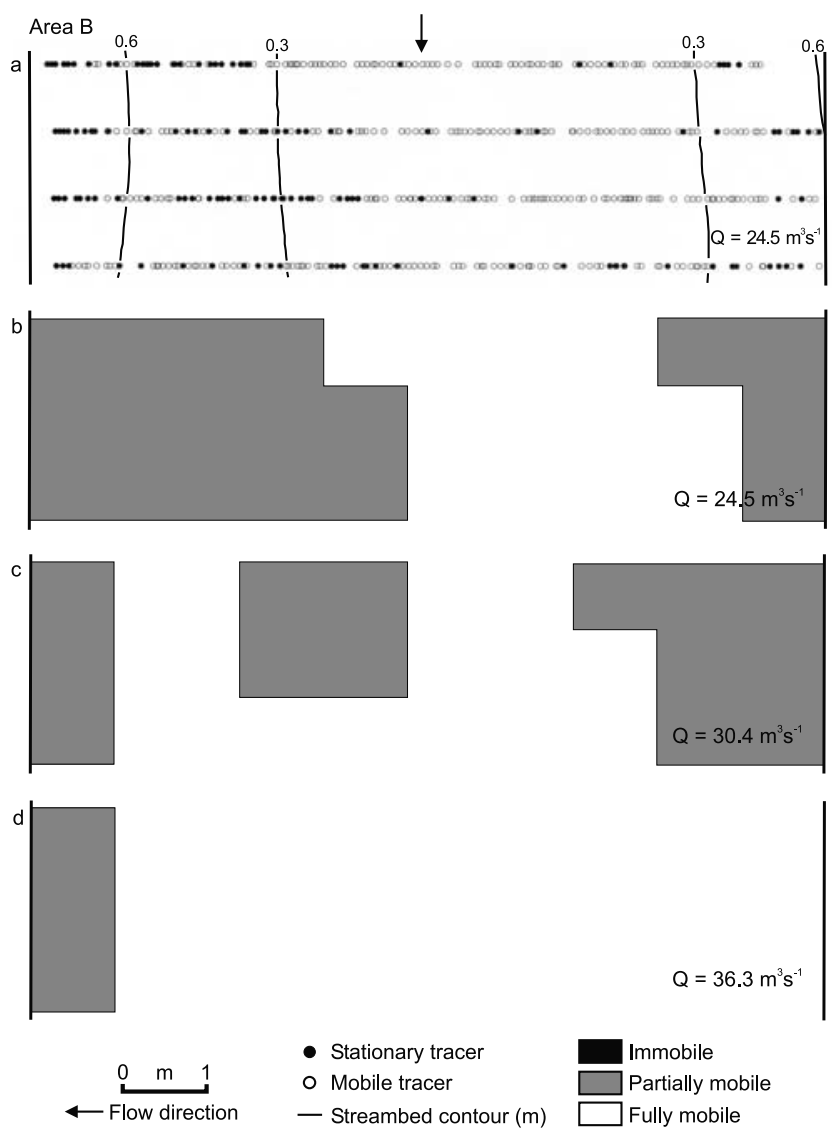

Figure 3. Maps for bed area B in upper deployment area. (a) Map indicating mobility of individual tracers for the 24.5 $\mathrm{m}^{3} \mathrm{~s}^{-1}$ peak and activity maps for (b) $24.5 \mathrm{~m}^{3} \mathrm{~s}^{-1}$ peak, (c) $30.4 \mathrm{~m}^{3} \mathrm{~s}^{-1}$ peak, and (d) $36.3 \mathrm{~m}^{3} \mathrm{~s}^{-1}$ peak. 
entire bed area following the $36.3 \mathrm{~m}^{3} \mathrm{~s}^{-1}$ flood (Figure 4c), which caused net degradation in the local area.

[30] Considering the upper deployment area as a whole, flows between about $50 \%$ and $70 \%$ bank-full discharge produced complete surface entrainment in about one third of the bed area incorporating the thalweg and partial transport over most of the remainder of the bed, except near the channel margin. At larger flows, the fully mobile region increased at the expense of partially mobile regions, with $51-70 \%$ of the bed area fully mobilized at flows reaching $85 \%$ bank-full and nearly complete surface mobilization near bank-full discharge.

[31] In the lower deployment area E, the $17.7 \mathrm{~m}^{3} \mathrm{~s}^{-1}$ peak produced a more spatially varied bed response (Figure $5 b)$. Partial mobility comprised $58 \%$ of the bed area, including most of the top and side of the gravel bar on the right side of the channel. Full surface entrainment occurred within or near the low-flow channel and on a portion of the bar. Two immobile areas, surrounded by a partially mobile unit, accounted for the remaining $7 \%$ of the bed area. Following the $36.3 \mathrm{~m}^{3} \mathrm{~s}^{-1}$ flood, $90 \%$ of the bed was classified as fully mobile (Figure 5c). The remaining area of partial mobility (Table 2) contained relatively large tracers (most $>90 \mathrm{~mm}$ ) that were buried up to $23 \mathrm{~cm}$ by the end of the flood.

[32] All four monitored areas show a similar pattern of increasing mobility with increasing flow (Figure 6) with a mix of immobile, partially mobile, and fully mobile regions persisting over a wide range of flow. The proportion within the three activity levels differs by less than $12 \%$, in general, when areas $\mathrm{A}$ and $\mathrm{B}$ and areas $\mathrm{D}$ and $\mathrm{E}$ are compared. In Figure 6 the onset of grain mobility is placed at slightly over $10 \%$ bank-full, based on field observations of minor move-
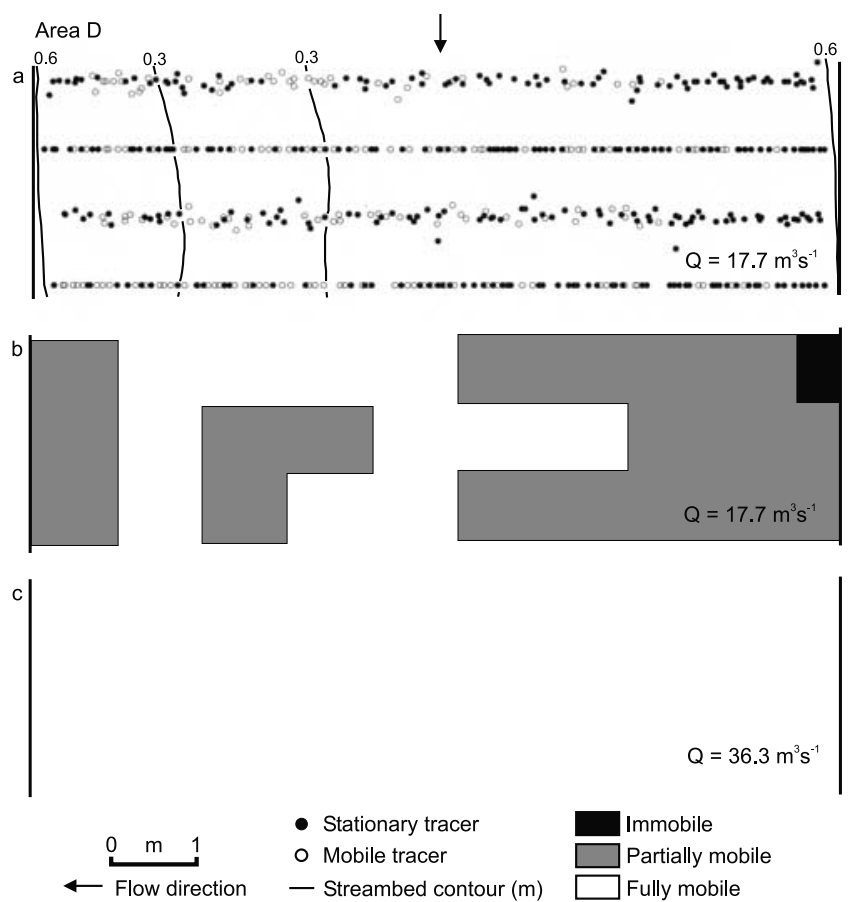

Figure 4. Maps for bed area $\mathrm{D}$ in upper deployment area. (a) Map indicating mobility of individual tracers for the 17.7 $\mathrm{m}^{3} \mathrm{~s}^{-1}$ peak and activity maps for (b) $17.7 \mathrm{~m}^{3} \mathrm{~s}^{-1}$ peak and (c) $36.3 \mathrm{~m}^{3} \mathrm{~s}^{-1}$ peak.
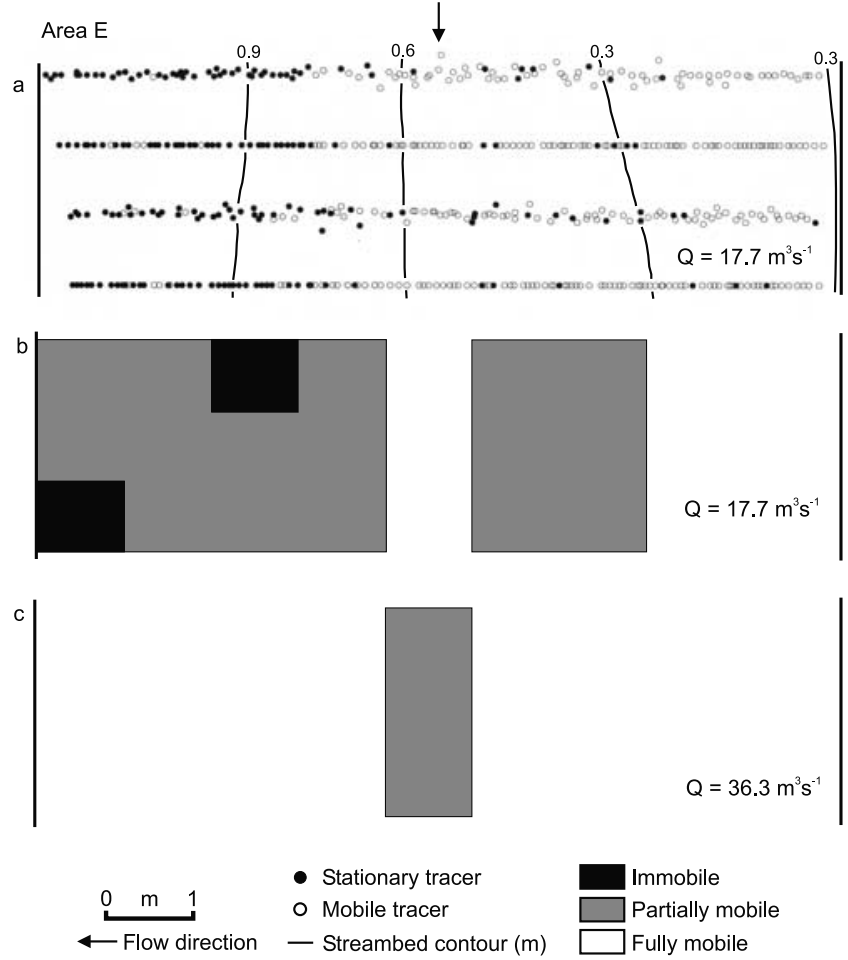

Figure 5. Maps for bed area $\mathrm{E}$ in lower deployment area. (a) Map indicating mobility of individual tracers for the 17.7 $\mathrm{m}^{3} \mathrm{~s}^{-1}$ peak and activity maps for (b) $17.7 \mathrm{~m}^{3} \mathrm{~s}^{-1}$ peak and (c) $36.3 \mathrm{~m}^{3} \mathrm{~s}^{-1}$ peak.

ment of tracer gravels at about $4 \mathrm{~m}^{3} \mathrm{~s}^{-1}$. Partial mobility persists over a substantial portion of the bed for flows up to $85 \%$ bank-full but largely vanishes near bank-full discharge. The largest flow observed was approximately bank-full and was observed at all four monitoring areas: in two cases the entire bed was fully mobile, and in the other two cases the bed retained a small area of partial mobility.

[33] In partially mobile regions of the bed, the active proportion of grains varies with both grain size and discharge. The active proportion of surface grains is plotted in Figure 7 as a function of grain size for the initial flow at each of the monitoring areas. In each case, the amount of bed area mapped as partially mobile was between $58 \%$ and $60 \%$ (Table 2). At areas A and B the flow of $24.5 \mathrm{~m}^{3} \mathrm{~s}^{-1}$ entrained $63 \%$ and $65 \%$ of the grains within the partial transport areas and grain entrainment exceeded $50 \%$ for sizes up to the 64- to $90-\mathrm{mm}$ size class (area A) and the 90to $128-\mathrm{mm}$ size class (area B) (Figures $7 \mathrm{a}$ and $7 \mathrm{~b}$ ). Increased activity of larger sizes in area B may be due in part to initial tracer placement on the surface (in contrast to the grain replacement used in area A), which is likely to lower the shear stress needed for entrainment [Church, 1978; Andrews, 1983]. At areas D and E the flow of $17.7 \mathrm{~m}^{3}$ $\mathrm{s}^{-1}$ entrained $56 \%$ and $52 \%$ of the grains within the partial transport areas and grain entrainment exceeded $50 \%$ for sizes up to the 32- to 45-mm size class (Figures $7 \mathrm{c}$ and $7 \mathrm{~d}$ ). Similarly, inactive grains within areas mapped as fully mobile (i.e., where $Y>0.9$ ) were drawn primarily from the coarsest size fractions. The small number of active grains within areas defined as immobile (i.e., where $Y<$ 0.1 ) were smaller than $64 \mathrm{~mm}$. The reduction of grain 

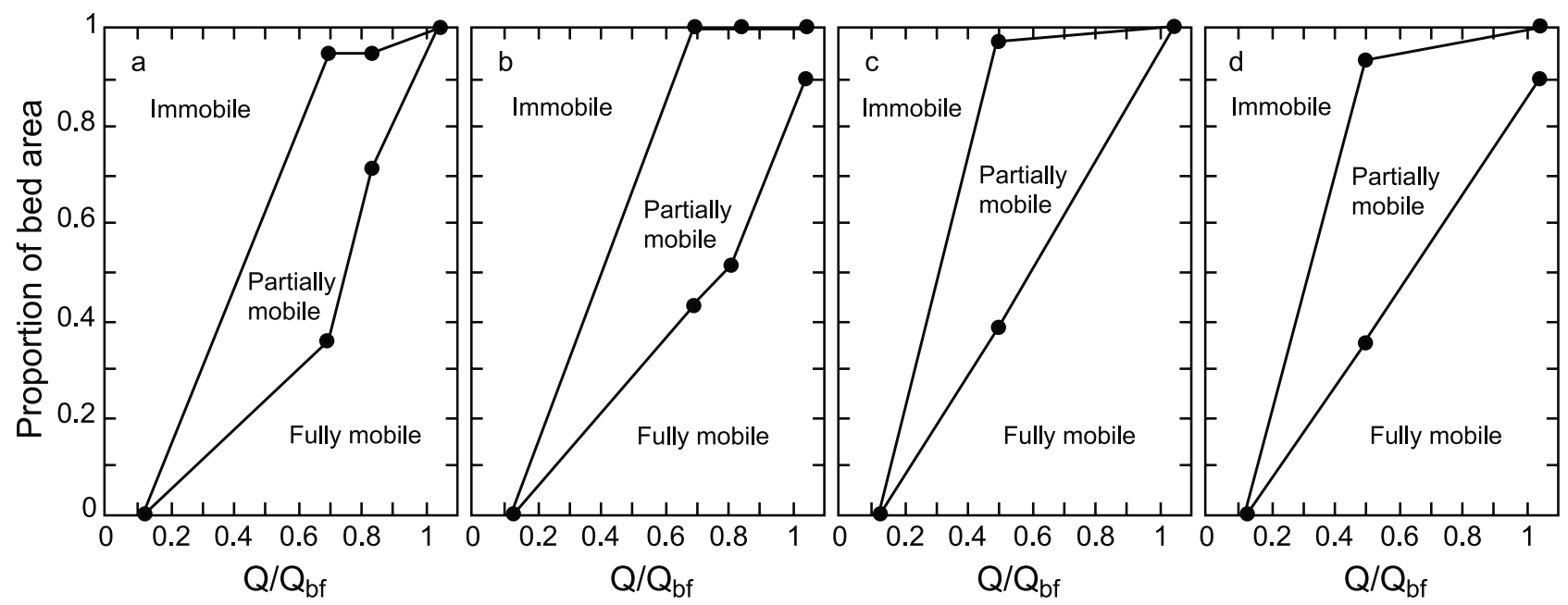

Figure 6. Proportional bed activity as a function of scaled peak discharge: (a) upper A area, (b) upper B area, (c) upper $\mathrm{D}$ area, and (d) lower $\mathrm{E}$ area. $Q$ is the maximum peak discharge for a given tracer recovery, and $Q_{b f}$ is the approximate bank-full discharge of $35 \mathrm{~m}^{3} \mathrm{~s}^{-1}$.

activity with grain size is consistent with earlier observations [Andrews and Erman, 1986; Ashworth and Ferguson, 1989; Wilcock and McArdell, 1997; Church and Hassan, 2002], and the increase in partially mobile grain size with increasing discharge is consistent with the flume observations of Wilcock and McArdell [1997].

[34] For all activity levels, some detail in the grain-size trends is sensitive to the spatial averaging employed. For example, by decreasing the width increment used to define bed activity along the tracer lines from 1.0 to $0.5 \mathrm{~m}$, all of the grains in the fully mobile portions would have been active (such that all sizes plot at 1.0 in Figure 7) in three of the four areas. A further reduction of the width increment to $0.25 \mathrm{~m}$ causes the fully mobile areas at all four sites to consist entirely of active grains. Changes in the width increment do not substantially alter the size-dependence of grain activity in the partially mobile regions. A $1.0-\mathrm{m}$ increment was selected in order to bring out the broader patterns of partial transport (Figures 2-5) amid considerable local complexity on the bed. The most pronounced deviations from systematic declining trends (Figure 7: 180$\mathrm{mm}$ fraction, area $\mathrm{A}$, and $128-$ and $180-\mathrm{mm}$ fractions, area E) appear to be partly the consequence of the entrainment of a few grains from small $(5-10)$ numbers of grains in these coarse sizes.

\section{Discussion and Conclusion}

[35] Distinct areas of grain mobility were observed in the gravel bed channel of Carnation Creek. During floods, all surface grains in some areas of the streambed can be entrained while a portion of the surface grains in other

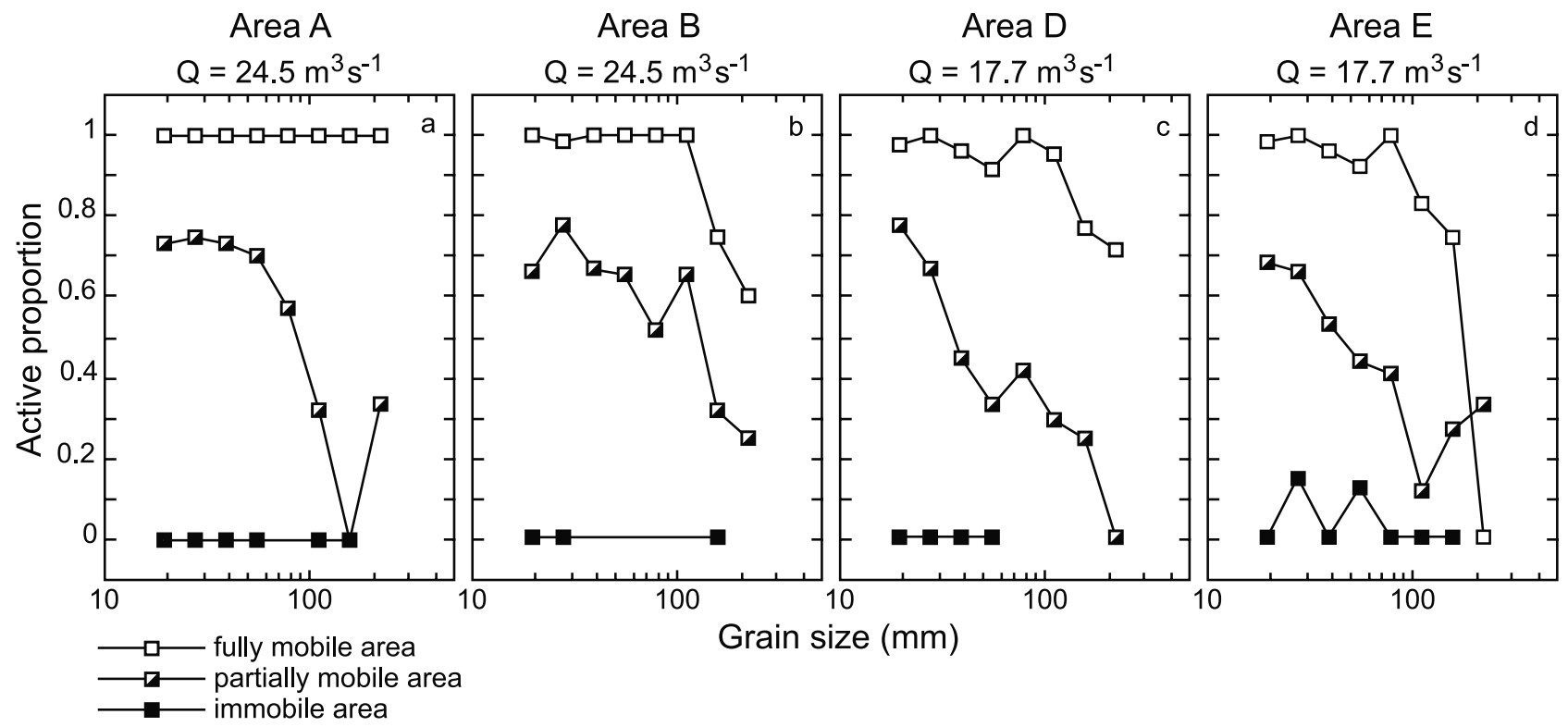

Figure 7. Active proportion of surface grains as a function of grain size; (a) upper A area, (b) upper B area, (c) upper D area, and (d) lower E area. 
areas can remain entirely inactive throughout the flood, a condition defined as partial transport. The extent of partially and fully mobile bed areas shifted with discharge. At flows between about $50 \%$ and $70 \%$ of the bank-full discharge, about $60 \%$ of the bed surface was in a state of partial transport, indicating that a portion of the surface grains remained entirely inactive throughout the flood. Nearly all surface grains were entrained in most of the remaining bed area, including the thalweg, except for small areas of immobile surface grains near the channel margin. During a flood that peaked at approximately $85 \%$ of bank-full discharge, the fully mobile region increased at the expense of partially mobile regions, although $25-50 \%$ remained in a state of partial transport. At a flow approximately equal to the bank-full discharge, nearly all grains on the entire bed surface were entrained. The 7-year return period of this flood magnitude indicates that complete mobilization of surface grains is not a frequent event.

[36] As surface grain entrainment increased with larger flood peaks, a systematic shift in mobility regions occurred. For the two smallest floods observed, the partial transport areas were located on bar surfaces between the zone surrounding the thalweg and the channel margin. Areas of full mobility were concentrated near the thalweg. As flow and transport increased, small immobile regions near the channel banks became partially mobile and the fully mobile region around the thalweg expanded, replacing partially mobile area. At a flow approximating bank-full discharge, the replacement of partial transport zones with fully mobile ones was nearly complete.

[37] Significant regions of partial mobility existed during the $30.4 \mathrm{~m}^{3} \mathrm{~s}^{-1}$ flood, which fills channel capacity to about $85 \%$ and occurs approximately every 2 years. The observation of partial transport at a flow of this frequency indicates that immobile and partially mobile portions of the gravel bed can persist from year to year. Moreover, the systematic shift in mobility regions establishes a spatial preference for sediment exchange because some bed areas experience greater grain activity more frequently. These two results have important implications for the rate of streambed armoring, the frequency and extent of subsurface flushing of fines, and the frequency and degree of impact of disturbance to the benthic community.

[38] When partial mobility dominated bed activity, bed material transport rates averaged 0.022 to $0.048 \mathrm{~kg} \mathrm{~m}^{-1} \mathrm{~s}^{-1}$ over the flood events, which exceeds the reference transport rate [Parker et al., 1982] by an order of magnitude. Instantaneous rates would clearly be higher. At a larger flow in which the region of partial mobility occupied approximately $25-50 \%$ of the bed area, average transport rates reached $0.078 \mathrm{~kg} \mathrm{~m}^{-1} \mathrm{~s}^{-1}$. Thus transport rates can be large in the presence of partial transport. Once complete surface grain mobilization was reached at two of the monitored bed areas and closely approximated at the other two areas, mean transport rates increased to $0.12 \mathrm{~kg} \mathrm{~m}^{-1} \mathrm{~s}^{-1}$.

[39] With the approach to full surface grain entrainment, the mean depth of sediment exchange reached 2 and 1.5 times the surface layer thickness in the upper and lower deployment areas, respectively, as judged from scour depths derived from scour indicators within $100 \mathrm{~m}$ of each deployment area and surface layer thicknesses defined by the local surface $D_{90}$ (values given above). Wilcock and McArdell
[1997] demonstrated that as surface grain entrainment approached full mobilization for their experimental sediment bed, the mean depth of sediment exchange approached 2 times the thickness of the surface layer. Results for Carnation Creek suggest that the approach of full surface grain mobilization is associated with depths of sediment exchange comparable to those expected from the experimental results.

[40] Within the partially mobile areas of the Carnation Creek streambed, the active proportion of surface grains declined with increasing grain size, as expected [Wilcock, 1997]. Moreover, the differences in activity among grain sizes appear to lessen with increasing flow. This demonstration of partial transport is a refinement over the results reported by Andrews and Erman [1986], Ashworth and Ferguson [1989], and Church and Hassan [2002], where all available tracers were considered regardless of the entrainment level of the tracer source area. Without spatial refinement, the active proportion of surface grains would be elevated whenever tracers from fully mobile areas are included. For Carnation Creek, active proportion-grain size trends using a strategy comparable to that of previous studies increases $Y_{i}$ by as much as 0.55 .

[41] Partial transport is defined relative to surface grain entrainment rather than transport rate. Size-selective fractional bed load transport rates (generally with transport grain size being finer than that of the bed) do not definitively establish the existence of partial transport. On the basis of Carnation Creek results, it appears likely that transport rates reported for natural channels in nonarid regions represent an ensemble of grains derived from a combination of partially and fully mobile source areas. In some rivers [e.g., Church and Hassan, 2002], transported material may be mostly advected into a given location over a relatively stable bed. Spatial variability in bed composition and topography influence both the entrainment frequency and the travel distance of mobile grains, making it especially difficult to link transport rate with the spatial extent and local variability of grain entrainment.

[42] Acknowledgments. Research in Carnation Creek was funded by the Natural Sciences and Engineering Research Council of Canada (grant awarded to M. Church) and the Geological Society of America (grants awarded to J.K.H.). The British Columbia Ministry of Forests provided logistical support by operating the Carnation Creek field station. S. Babakaiff, R. Batalla, A. Collett, B. Eaton, D.Ham, B. Killiam, J. Matechuk, C. Nistor, S. Sterling, K. Trainor, S. Tsang, and B. Waddington assisted with fieldwork. Work on this paper began while J.K.H. was on sabbatical leave at Johns Hopkins University. We thank Mike Church for reviewing a draft manuscript and two anonymous reviewers for comments that helped clarify several points in the paper.

\section{References}

Andrews, E. D., Entrainment of gravel from naturally sorted riverbed material, Geol. Soc. Am. Bull., 94, 1225-1231, 1983.

Andrews, E. D., and D. C. Erman, Persistence in the size distribution of surficial bed material during an extreme snowmelt flood, Water Resour. Res., 22, 191-197, 1986.

Ashworth, P. J., and R. I. Ferguson, Size-selective entrainment of bed load in gravel bed streams, Water Resour. Res., 25, 627-634, 1989.

Carling, P. A., Bed stability in gravel streams, with reference to stream regulation and ecology, in River Channels: Environment and Process, Spec. Publ. Ser, vol. 17, edited by K. S. Richards, pp. 321-347, Inst. of Br. Geogr., Oxford, England, 1987.

Carling, P. A., Bedload transport in two gravel-bedded streams, Earth Surf. Processes Landforms, 14, 27-39, 1989. 
Church, M., Palaeohydrological reconstructions from a Holocene valley fill, in Fluvial Sedimentology, edited by A. D. Miall, pp. 743-772, Can. Soc. of Pet. Geol., Calgary, Alta., 1978.

Church, M., Fine sediments in small streams in coastal British Columbia: A review of research progress, in Proceedings of the Carnation Creek and Queen Charlotte Islands Fish/Forestry Workshop: Applying 20 Years of Research to Management Solutions, edited by D. L. Hogan, P. J. Tschaplinski, and S. Chatwin, pp. 119-133, B. C. Minist. of For., Victoria, Canada, 1998

Church, M., and M. A. Hassan, Mobility of bed material in Harris Creek, Water Resour. Res., 38(11), 1237, doi:10.1029/2001WR000753, 2002.

Dryburgh, J. G., Carnation Creek logging and silvicultural treatment program, in Carnation Creek Workshop: A 10-Year Review, edited by G. F. Hartman, pp. 36-44, Pac. Biol. Stn., Nanaimo, B. C., Canada, 1982.

Ferguson, R. I., and S. J. Wathen, Tracer-pebble movement along a concave river profile: Virtual velocity in relation to grain size and shear stress, Water Resour. Res., 34, 2031-2038, 1998.

Haschenburger, J. K., Scour and fill in a gravel-bed channel: Observations and stochastic models, Ph.D. thesis, 144 pp., Univ. of B. C., Vancouver, Canada, 1996.

Haschenburger, J. K., A probability model of scour and fill depths in gravel-bed channels, Water Resour. Res., 35, 2857-2869, 1999.

Haschenburger, J. K., and M. Church, Bed material transport estimated from the virtual velocity of sediment, Earth Surf. Processes Landforms, 23, 791-808, 1998

Hassan, M. A., M. Church, and A. P. Schick, Distance of movement of coarse particles in gravel bed streams, Water Resour. Res., 27, 503-511, 1991.

Jackson, W. L., and R. L. Beschta, A model of two-phase bedload transport in an Oregon Coast Range stream, Earth Surf. Processes Landforms, 7, $517-527,1982$

Kenworthy, S. T., and P. R. Wilcock, Sediment entrainment and displacement of aquatic insect larvae: Results from a laboratory study, in GravelBed Rivers 2000, CD ROM, edited by T. Nolan and C. Thorne, special publication, N. Z. Hydrol. Soc., Wellington, 2001.

Lewis, C. P., Introduction: Workshop outline and experimental design, in Proceedings of the Carnation Creek and Queen Charlotte Islands Fish/ Forestry Workshop: Applying 20 Years of Research to Management Solutions, edited by D. L. Hogan, P. J. Tschaplinski, and S. Chatwin, pp. $5-$ 11, B. C. Minist. of For., Victoria, Canada, 1998.
Lisle, T. E., J. M. Nelson, J. Pitlick, M. A. Madej, and B. L. Barkett, Variability of bed mobility in natural gravel-bed channels and adjustments to sediment load at local and reach scales, Water Resour. Res., $36,3743-3755,2000$

Oswald, E. T., Preharvest vegetation and soils of Carnation Creek watershed, in Carnation Creek Workshop: A 10-Year Review, edited by G. F. Hartman, pp. 17-35, Pac. Biol. Stn., Nanaimo, B. C., Canada 1982.

Parker, G., P. C. Klingeman, and D. G. McLean, Bedload and size distribution in paved gravel-bed streams, J. Hydraul. Div. Am. Soc. Civ. Eng., 108, 544-571, 1982.

Scrivener, J. C., The Carnation Creek experimental watershed project: A description and history from 1970 to 1986, in Applying 15 Years of Carnation Creek Results, edited by T. W. Chamberlin, pp. 1-10, Carnation Creek Steering Comm., Pac. Biol. Stn., Nanaimo, B. C., Canada, 1987.

Stelczer, K., Bed-Load Transport, Water Resour. Publ., Highlands Ranch, Colo., 1981

Wilcock, P. R., The components of fractional transport rate, Water Resour Res., 33, 247-258, 1997.

Wilcock, P. R., Sediment maintenance flows: Feasibility and basis for prescription, in Gravel-Bed Rivers in the Environment, edited by P. C. Klingeman et al., pp. 609-632, Water Resour. Publ., Highlands Ranch, Colo., 1998 .

Wilcock, P. R., and B. W. McArdell, Surface-based fractional transport rates: Mobilization thresholds and partial transport of a sand-gravel sediment, Water Resour. Res., 29, 1297-1312, 1993.

Wilcock, P. R., and B. W. McArdell, Partial transport of a sand/gravel sediment, Water Resour. Res., 33, 235-245, 1997.

Wilcock, P. R., A. F. Barta, C. C. Shea, G. M. Kondolf, W. V. G. Matthews, and J. Pitlick, Observations of flow and sediment entrainment on a large gravel-bed river, Water Resour. Res., 32, 2897-2909, 1996.

J. K. Haschenburger, School of Geography and Environmental Science, University of Auckland, PB 92019, Auckland, New Zealand. (j.haschenburger@auckland.ac.nz)

P. R. Wilcock Department of Geography and Environmental Engineering, Johns Hopkins University, Baltimore, MD 21218, USA. 